\title{
Relationship of Glucagon Suppression by Insulin and Somatostatin to the Ambient Glucose Concentration
}

\author{
A. Starke, T. Imamura, and R. H. Unger \\ Center for Diabetes Research and Department of Internal Medicine, The University of Texas Health Science \\ Center at Dallas, Dallas, Texas 75235; and Veterans Administration Medical Center, Dallas, Texas 75216
}

\begin{abstract}
The glucagon-suppressing activity of insulin and somatostatin were compared at high and low glucose concentrations. In normal dogs made hyperglucagonemic by phloridzin pretreatment, insulin and somatostatin suppressed glucagon at rates of $47 \pm 8$ and $35 \pm 8 \% / h$ (NS), respectively, despite profound hypoglycemia. In severely hyperglycemic alloxan-diabetic dogs, insulin and somatostatin suppressed glucagon at rates of $48 \pm 13$ and $54 \pm 6 \%$ / $h$, respectively, not different from the nondiabetic dogs. After phloridzin pretreatment to eliminate hyperglycemia in the diabetic dogs, insulin and somatostatin suppressed $51 \pm 8$ and $31 \pm 10 \% / h$ (NS), respectively. Glucose infused in the phloridzinpretreated insulin-deprived group suppressed glucagon only partially; insulin was required to reduce it further. We conclude (a) that insulin and somatostatin suppress glucagon at similar rates irrespective of ambient glucose levels, and (b) that diabetic hyperglucagonemia represents the summation of stimulation by insulin lack minus suppression by the associated hyperglycemia.
\end{abstract}

\section{Introduction}

The high glucagon levels that characterize untreated diabetes mellitus in humans and animals are promptly suppressed both by insulin (1-6) and somatostatin (7-9). Somatostatin is believed to suppress glucagon secretion by a direct action on beta cells that is independent of the ambient glucose concentration (1-6). It is not clear, however, if insulin, first reported by Samols et al. (10) in 1972 to suppress glucagon secretion, does so via a direct glucose-independent effect or by enhancing in alpha cells the transport of glucose (11), which can also suppress glucagon secretion, even in the absence of insulin (12). Previous in vivo studies of glucagon suppression by insulin do not permit clear differentiation between a direct or a glucose-mediated action. This stems from the fact that if insulin is infused without glucose, the resulting hypoglycemia stimulates glucagon secretion (13), thereby masking or overriding its suppressive action. On the other hand, if hypoglycemia is prevented by euglycemic clamping of glucose levels during insulin infusion (14), it becomes difficult to dissociate the effects of insulin from those of the infused glucose. In vitro systems can circumvent such ambiguity, but since $\sim 500$ times as much insulin is required to suppress glucagon

Address reprint requests to Dr. Unger, Center for Diabetes Research, University of Texas Health Science Center, 5323 Harry Hines Blvd., Dallas, TX 75235. 1986.

Received for publication 6 June 1986 and in revised form 3 September

J. Clin. Invest.

(c) The American Society for Clinical Investigation, Inc.

0021-9738/87/01/0020/05 \$1.00

Volume 79, January 1987, 20-24 in vitro (6) as in vivo (14), their relevance to in vivo suppression can be questioned.

To reexamine in vivo the relative importance of the ambient glucose concentration in insulin-induced and somatostatin-induced suppression of glucagon, we compared insulin and somatostatin effects on plasma glucagon at both high and low levels of glycemia. The results are consistent with a glucagon-suppressing activity for insulin that is independent of the ambient glucose concentration and thus comparable in certain respects to that of somatostatin.

\section{Methods}

The experiments were performed in six conscious normal male mongrel dogs weighing 22-29 kg. Experimental conditions conformed to stringent considerations of animal welfare. Only clinically healthy dogs were used.

Phloridzin (Sigma Chemical Co., St. Louis, MO) in a dose of $2 \mathrm{~g}$ as a $40 \%$ solution in propylene glycol was administered subcutaneously 40 and $16 \mathrm{~h}$ before an experiment. In previously normal dogs this caused glycosuria averaging $145 \pm 18 \mathrm{~g} / 24 \mathrm{~h}$ and a decline in fasting glucose levels to an average of $62 \pm 2 \mathrm{mg} / \mathrm{dl}$.

Severe insulin-requiring diabetes mellitus was induced in six normal dogs by a single intravenous injection of alloxan $(70-75 \mathrm{mg} / \mathrm{kg}$ of body weight). Experiments were begun 3 mo or more thereafter. The daily insulin dose, which ranged from 24 to $36 \mathrm{U}$ of isophane insulin (Eli Lilly $\&$ Co., Indianapolis, IN), was discontinued $88 \mathrm{~h}$ before an experiment so as to produce a profound insulin deficiency. On a second occasion the same dogs were again studied $48 \mathrm{~h}$ after discontinuation of insulin but without hyperglycemia. This had been corrected by means of two subcutaneous injections of $2 \mathrm{~g}$ of the glucuretic agent phloridzin (Sigma Chemical Co.), administered as a $40 \%$ solution in propylene glycol 40 and $16 \mathrm{~h}$ before the start of an experiment. Phloridzin increased the glycosuria from $244 \pm 68 \mathrm{~g} / 24 \mathrm{~h}$ to $422 \pm 73 \mathrm{~g} / 24 \mathrm{~h}$ and thereby reduced the fasting plasma glucose level from $357 \pm 17$ to $80 \pm 7 \mathrm{mg} / \mathrm{dl}$.

Experiments were conducted as follows. After a $20-\mathrm{h}$ overnight fast a catheter was inserted via a saphenous vein into the inferior vena cava for blood sampling. Test solutions were infused via a teflon catheter inserted into a crural vein of a foreleg. Insulin (Iletin II pork; Eli Lilly \& Co.) was prepared in $0.9 \% \mathrm{NaCl}$ containing $0.2 \%$ bovine albumin. The infusion rate was adjusted so as to deliver $0.25,0.5,1.0,2.5,5.0$, or $7.5 \mathrm{mU} / \mathrm{kg}$ per min). Somatostatin (synthetic SS-14; Clin-Midy Co., Montpellier, France) was dissolved in $0.9 \% \mathrm{NaCl}$ containing $0.2 \%$ bovine albumin. Infusion rates were adjusted so as to deliver amounts equimolar to insulin $(1.67,3.33,6.67,16.70,33.3$, and $50.0 \mathrm{pmol} / \mathrm{kg}$ per min). Plasma glucose was analyzed on a spectrophotometer (System 103; Gilford Instrument Laboratories, Inc., Oberlin, $\mathrm{OH}$ ). Glucagon was measured by a previously described technique (15) and insulin by a modification (16) of the method of Yalow and Berson (17).

\section{Results}

Comparison of effects of insulin and somatostatin on the hyperglucagonemia of chronic phloridzin-induced hypoglycemia in normal dogs. In normal control dogs, insulin infused without glucose resulted in the expected rise in plasma glucagon when 
the mean plasma glucose levels declined below $38 \pm 4 \mathrm{mg} / \mathrm{dl}$ (Fig. 1), confirming earlier work (13). However, when five of the same normal dogs were pretreated with phloridzin, which produced a constant mild hypoglycemia ( $63 \pm 3$ vs. $95 \pm 5 \mathrm{mg} / \mathrm{dl} ; P<0.01$ ), hyperglucagonemia $(427 \pm 100$ vs. $80 \pm 6 \mathrm{pg} / \mathrm{ml} ; P<0.05)$ and fasting hypoinsulinemia $(4.9 \pm 0.4$ vs. $13.2 \pm 1.7 \mu \mathrm{U} / \mathrm{ml} ; P$ $<0.001$ ), insulin infused without glucose suppressed glucagon. The plasma insulin levels attained by infusing insulin at the same progressively increasing rates were approximately the same in the phloridzin-treated group (Fig. 2) as in the control experiments (Fig. 1). The elevated glucagon levels began to decline after the first 10 min of insulin infusion, at which time plasma insulin had risen only slightly above the normal fasting insulin level $(14.6 \pm 2.7 \mu \mathrm{U} / \mathrm{ml})$. Glucagon continued to fall despite declining glucose levels, and reached the $30 \mathrm{mg} / \mathrm{dl}$ range. (In the insulin hypoglycemia experiments in Fig. 1, the peak rise in glucagon level during maximum hypoglycemia of $41 \pm 4 \mathrm{mg} / \mathrm{dl}$ was $223 \pm 33 \mathrm{pg} / \mathrm{ml}$; this is not significantly different from the nadir of $172 \pm 10 \mathrm{pg} / \mathrm{ml}$ in Fig. 2 in the insulin-infused phloridzintreated dogs $[P>0.05]$.) The rate of glucagon decline during

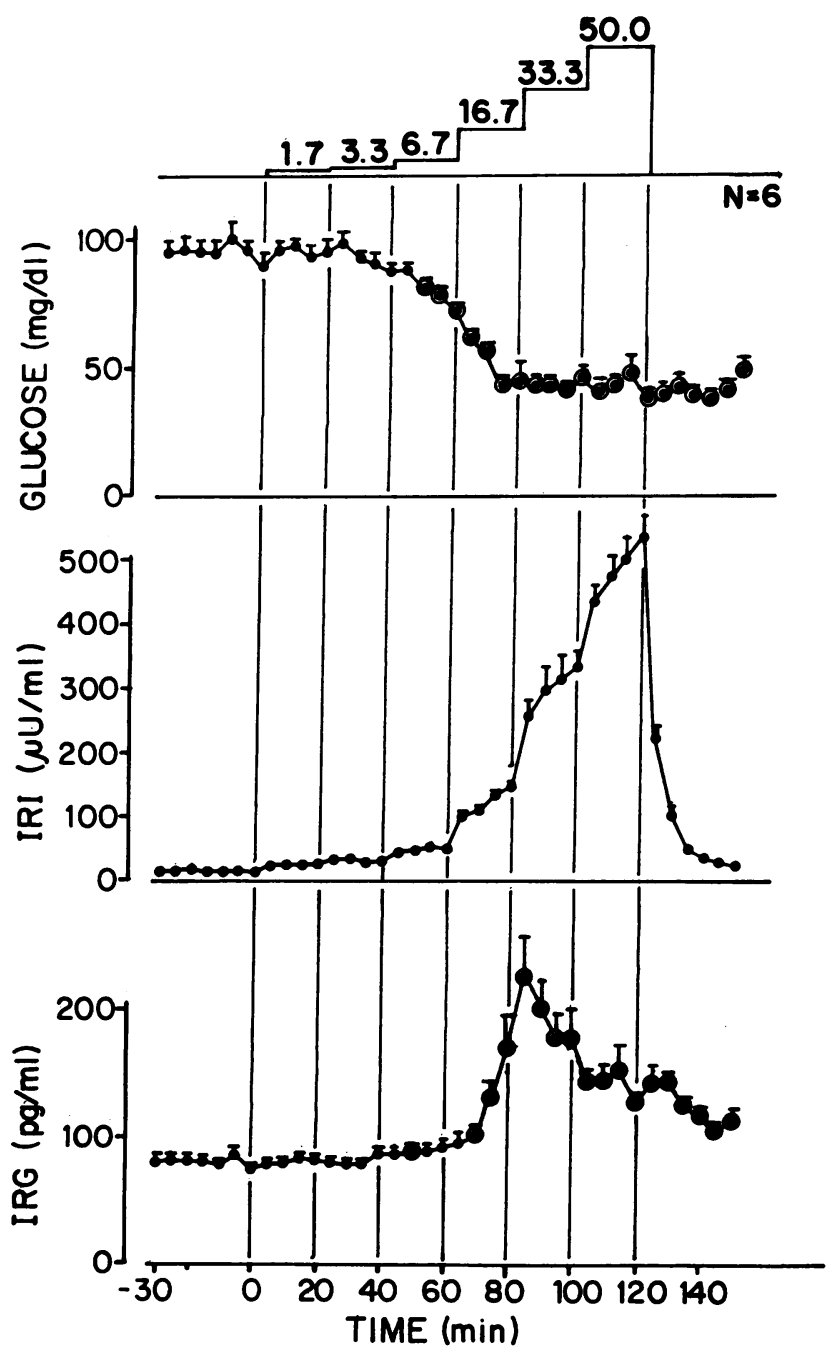

Figure 1. The effects of insulin infusion on plasma glucagon levels in normal dogs. IRI, immunoreactive insulin; IRG, immunoreactive glucagon. (Solid circles) $P<0.05$ vs. baseline value. Infusion rate in picomoles per kilogram per minute is indicated above.

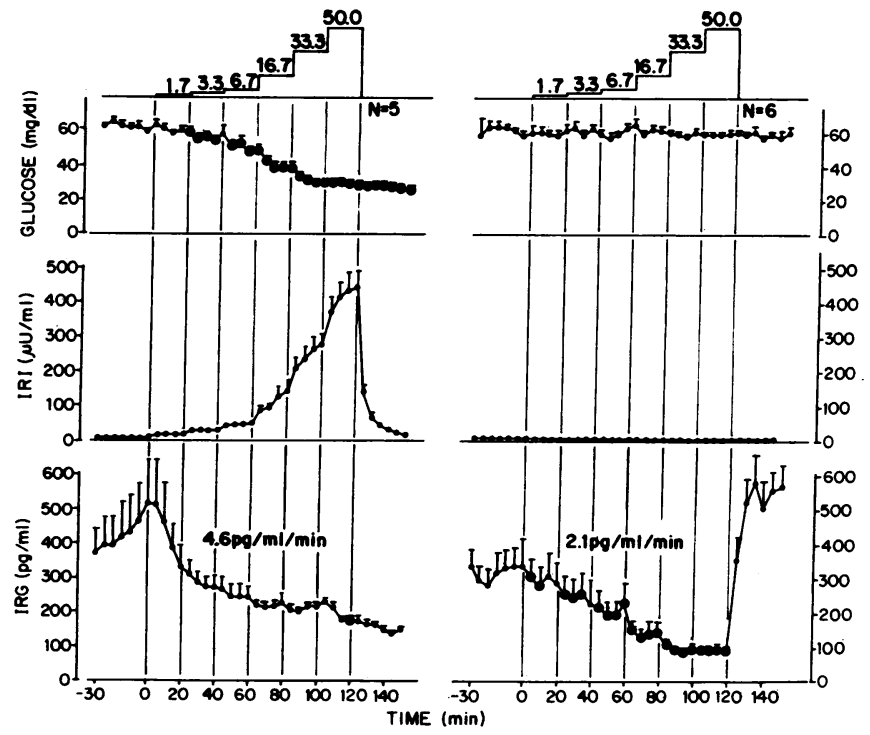

Figure 2. The effects of insulin (left panel) and somatostatin on the hyperglucagonemia of normal dogs made mildly hypoglycemic by pretreatment with phloridzin. IRI, immunoreactive insulin; IRG, immunoreactive glucagon. (Solid circles) $P<0.05$ vs. baseline value. Infusion rate (picomoles per kilogram per minute) is indicated above. The values in lower panels represent the rate of IRG decline.

the first $60 \mathrm{~min}$ was $4.6 \pm 1.9 \mathrm{pg} / \mathrm{ml}$ per $\mathrm{min}$, or $47 \pm 8 \% / \mathrm{h}$. Glucagon suppression persisted after discontinuation of insulin.

In the same five dogs (plus a sixth dog) studied after phloridzin pretreatment, somatostatin was infused at rates equimolar to those of the insulin infusion (Fig. 2). During the first $60 \mathrm{~min}$ of somatostatin infusion glucagon declined at a rate of $2.1 \pm 0.7$ $\mathrm{pg} / \mathrm{ml}$ per $\mathrm{min}$ or $35 \pm 8 \% / \mathrm{h}$, not significantly different from the rates observed during insulin infusion $(P>0.05)$, to a mean level of $92 \pm 15 \mathrm{pg} / \mathrm{ml}$. This level was significantly below the plateau of $172 \pm 10 \mathrm{pg} / \mathrm{ml}$ observed in the insulin-treated dogs after $60 \mathrm{~min}(P<0.01)$ (perhaps because hypoglycemia was not present) and did not differ from the fasting glucagon level of $80 \pm 6$ $\mathrm{pg} / \mathrm{ml}$ obtained in normal dogs $(P>0.05)$. In contrast to the persistence of suppression after discontinuation of insulin, there was an abrupt rebound in glucagon upon termination of the somatostatin infusion.

Comparison of effects of insulin and somatostatin on the hyperglucagonemia of hyperglycemic insulin-deprived alloxan diabetic dogs. To compare the glucagon-suppressing actions of insulin and somatostatin in a setting of steady state hyperglycemia, insulin was infused in insulin-deprived diabetic dogs whose fasting glucose level averaged $371 \pm 28 \mathrm{mg} / \mathrm{dl}$. There was prompt suppression of glucagon, at a rate of $4.7 \pm 1.7 \mathrm{pg} / \mathrm{ml} \mathrm{per}$ $\min$ or $48 \pm 13 \% / \mathrm{h}$. The values became significantly different from the baseline level at $100 \mathrm{~min}$, a point at which insulin levels had risen to $63 \pm 15 \mu \mathrm{U} / \mathrm{ml}$. Glucagon reached a nadir of $103 \pm 8 \mathrm{pg} /$ $\mathrm{ml}$ at $120 \mathrm{~min}$, at which time the infusion was terminated. There was no significant rebound in glucagon levels.

By contrast, somatostatin, which did not alter plasma glucose levels, elicited a significant decline in plasma glucagon within $25 \mathrm{~min}(P<0.05)$. The decline continued at a rate of $3.9 \pm 1.4$ $\mathrm{pg} / \mathrm{ml}$ per min or $54 \pm 6 \% / \mathrm{h}$ to a nadir of $68 \pm 7 \mathrm{pg} / \mathrm{ml}$ at 120 min, not significantly different from insulin $(P>0.05)$. Termination of the somatostatin infusion at this point resulted in a brisk rebound (Fig. 3). 


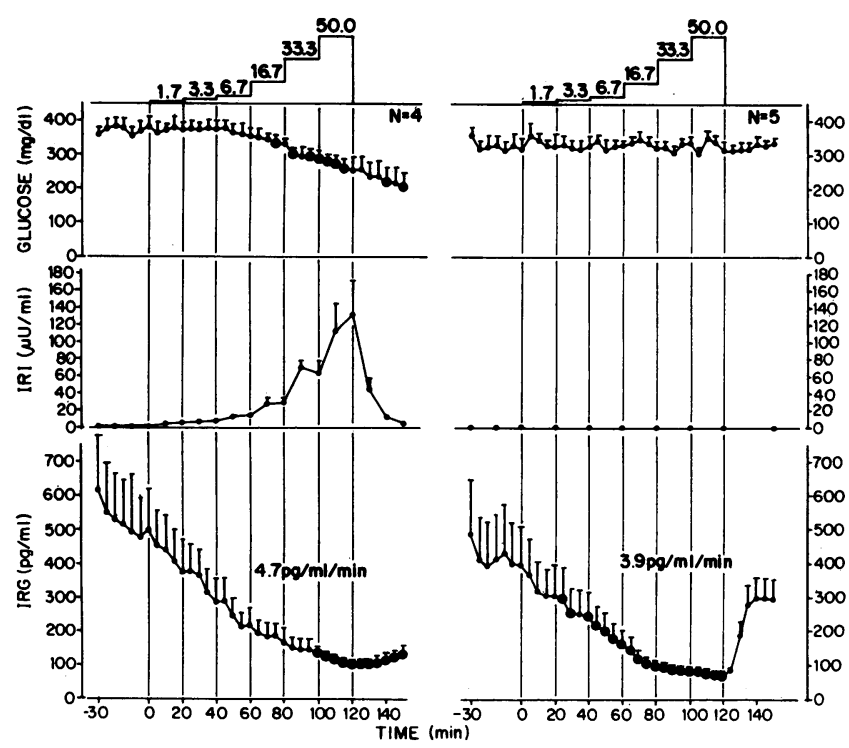

Figure 3. Effects of insulin (left panel) and somatostatin on the hyperglucagonemia of insulin-deprived alloxan-diabetic dogs with hyperglycemia. IRI, immunoreactive insulin; IRG, immunoreactive glucagon. (Solid circles) $P<0.05$ vs. baseline value. Infusion rate in picomoles per kilogram per minute is indicated above. The values in lower panels represent the rate of IRG decline.

Comparison of effects of insulin and somatostatin on the hyperglucagonemia of insulin-deprived alloxan-diabetic dogs made normoglycemic by phloridzin pretreatment. To compare insulinand somatostatin-induced glucagon suppression in the absence of hyperglycemia in the same insulin-deprived diabetic dogs, they were restudied after pretreatment with phloridzin. Despite $88 \mathrm{~h}$ of insulin deprivation and a lack of measurable insulin in their plasma, the fasting glucose level averaged only $77 \pm 5 \mathrm{mg} /$ dl. During insulin infusion glucagon again declined promptly to values that became statistically significant at $75 \mathrm{~min}$, at which time plasma insulin had risen to only $22.3 \pm 5.6 \mu \mathrm{U} / \mathrm{ml}$. Glucagon declined at a rate of $9.4 \pm 3.5 \mathrm{pg} / \mathrm{ml}$ per min or $51 \pm 8 \% / \mathrm{h}$ to a nadir of $173 \pm 23 \mathrm{pg} / \mathrm{ml}$ at $120 \mathrm{~min}$, when the insulin infusion was terminated (Fig. 4).

The infusion of somatostatin elicited a decline in glucagon levels at a rate of $5.5 \pm 3.4 \mathrm{pg} / \mathrm{ml}$ per min or $31 \pm 10 \% / \mathrm{h}$. This was not statistically different from the rate of decline during insulin infusion. The minimal glucagon level was $258 \pm 79 \mathrm{pg} /$ $\mathrm{ml}$ at $120 \mathrm{~min}$. At this point the somatostatin infusion was terminated and there was a prompt rebound to $\sim 1,400 \mathrm{pg} / \mathrm{ml}$.

Comparison of the effect of glucose alone and glucose plus insulin in insulin-deprived alloxan-diabetic dogs made normoglycemic by phloridzin. The recent demonstration that glucose can suppress glucagon secretion in the absence of insulin in severely diabetic animals made euglycemic by phloridzin (12) conflicted with earlier evidence that glucagon levels in diabetes could not be suppressed by glucose unless insulin was present $(1,11)$. However, in insulin-deprived alloxan-diabetic dogs pretreated with phloridzin (Fig. 5), baseline glucagon levels averaged $648 \pm 138 \mathrm{pg} / \mathrm{ml}$, compared with their baseline of $452 \pm 60 \mathrm{pg} /$ $\mathrm{ml}$ when the same insulin-deprived dogs were hyperglycemic. While not statistically significant, the difference raised the possibility that steady state hyperglycemia had partially reduced the hyperglucagonemia caused by the insulin deficiency. Hyperglycemia was, therefore, induced in normoglycemic phloridzinpretreated diabetic dogs by infusing glucose at a progressively

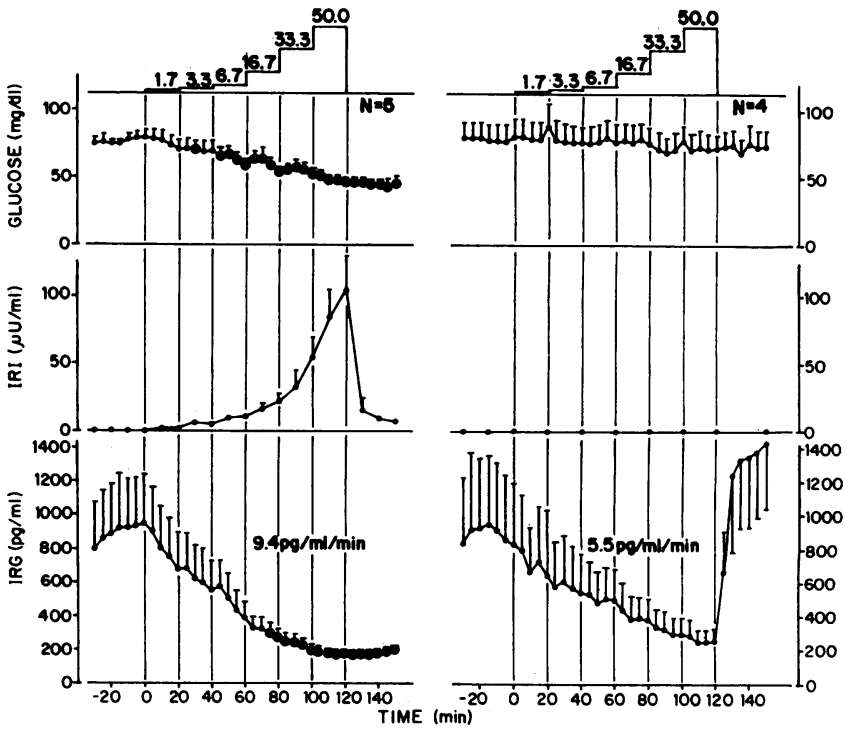

Figure 4. The effects of insulin (left panel) and somatostatin in insulin-deprived alloxan diabetic dogs made normoglycemic by pretreatment with phloridzin. IRI, immunoreactive insulin; IRG, immunoreactive glucagon. (Solid circles) $P<0.05$ vs. baseline value. Infusion rate in picomoles per kilogram per minute is indicated above. The values in lower panels represent the rate of IRG decline.

increasing rate. A prompt decline in glucagon at a rate of $5.0 \pm 1.3$ $\mathrm{pg} / \mathrm{ml}$ per min or $40 \pm 7 \% / \mathrm{h}$ (Table I) began within $10 \mathrm{~min}$ from a baseline level of $648 \pm 138 \mathrm{pg} / \mathrm{ml}$ to a nadir of $303 \pm 81 \mathrm{pg} / \mathrm{ml}$, but declined no further during the 4-h period of hyperglycemia between 200 and $1,000 \mathrm{mg} / \mathrm{dl}$. This nadir was not significantly different $(P>0.05)$ from the mean baseline level of $452 \pm 60 \mathrm{pg} /$ $\mathrm{ml}$ when the dogs had been spontaneously hyperglycemic.

These experiments were repeated in the same dogs, but insulin was added midway in the experiment. Glucagon was suppressed to a nadir of $321 \pm 19 \mathrm{pg} / \mathrm{ml}$ by glucose alone at $120 \mathrm{~min}$; infusion of insulin at a rate of $7.5 \mathrm{mU} / \mathrm{kg}$ per min at this point caused prompt further suppression of glucagon to a nadir of $141 \pm 24 \mathrm{pg} / \mathrm{ml}(P<0.01)$ (Fig. 5). However, the latter value was still significantly above the normal fasting glucagon level of dogs $(P<0.05)$.

Comparison of glucagon lowering by insulin and somatostatin at various plasma glucose concentrations. The glucagon-lowering action of insulin and of somatostatin demonstrated in the foregoing experiments are compared in Table I both as picograms per milliliter per minute and as percent of baseline per hour. There were no significant differences attributable to a difference in the glycemic ambience for either hormone; nor were there differences between the effects of the two hormones in any of the three glycemic ambiences.

\section{Discussion}

The goal of this study was to determine if the glucagon-lowering action of insulin in vivo is related to the ambient glucose concentration, as might be expected if insulin action involves enhancement of glucose uptake in alpha cells, or if it falls in the same glucose-independent direct category as somatostatin. If insulin stimulation of glucose uptake by alpha cells plays an important role in glucagon suppression, one might expect that the action of insulin would be greater at hyperglycemic than at hypoglycemic glucose levels. However, glucagon declined during insulin infusion at approximately the same rate in insulin-de- 

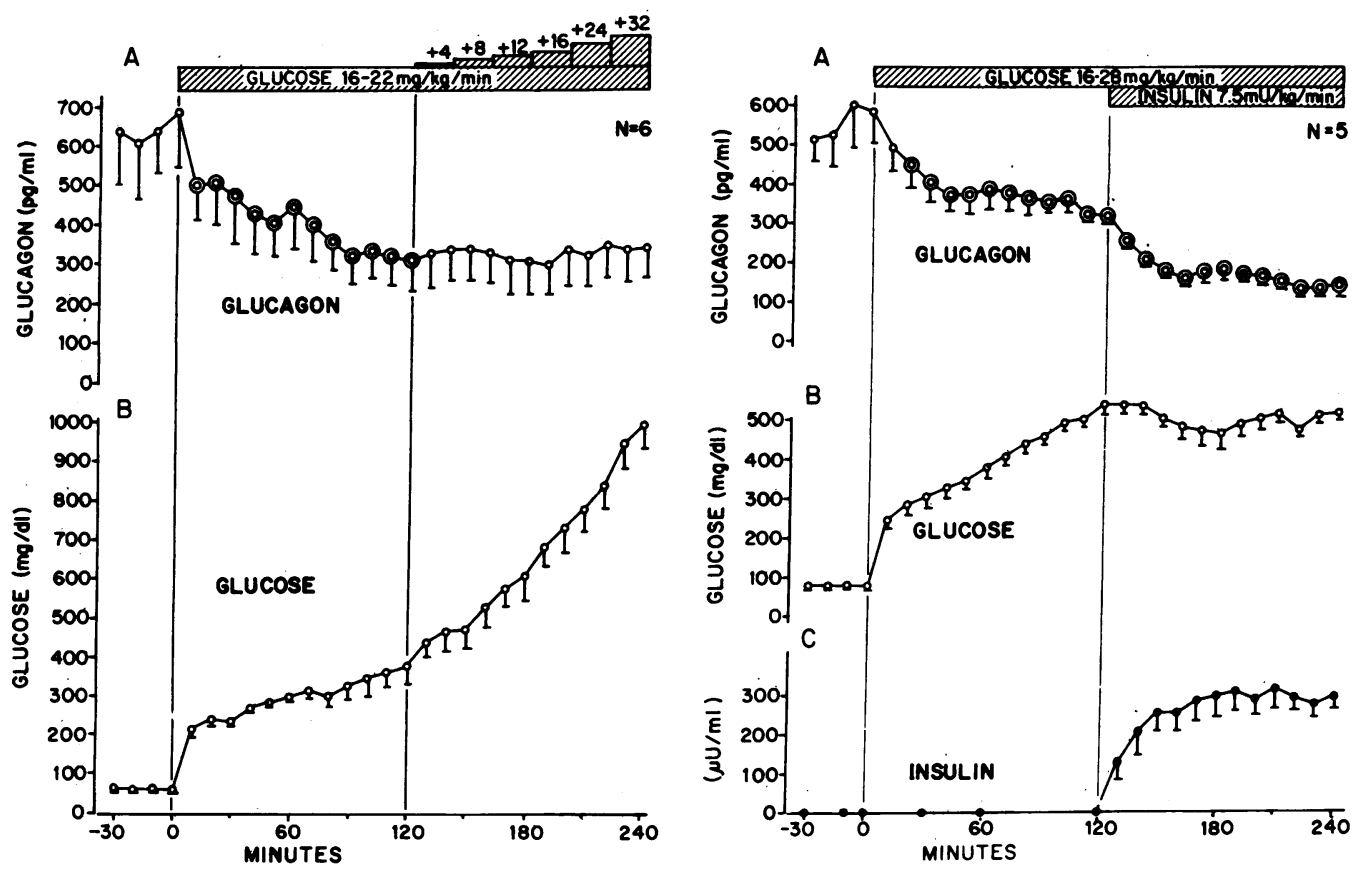

Figure 5. (Left) Effect of hyperglycemia induced by intravenous glucose infusion on the hyperglucagonemia of insulin-deprived alloxan-diabetic dogs made normoglycemic by phloridzin pretreatment. After $2 \mathrm{~h}$ of moderately severe hyperglycemia, further progressive increments in glucose infusion rate raised the glucose values to $1,000 \mathrm{mg} / \mathrm{dl}$ without suppressing glucagon levels. (Right) When insulin is superinfused at the 120min point, glucagon is significantly suppressed below the value observed at $120 \mathrm{~min}$. ๑ Statistically significant difference from the preceding baseline $(P<0.05)$.

prived diabetic dogs whether they were hyperglycemic or made normoglycemic by phloridzin pretreatment. The rates of glucagon decline in the diabetic dogs were no different from those of normal dogs made mildly hypoglycemic and hyperglucagonemic by phloridzin pretreatment. This was the case whether expressed as picograms per milliliter per minute or as percent of the baseline level. Although "big plasma glucagon" was not measured and could affect the baseline and hence the percent decline from baseline, it is usually low in dogs and varies little from week to week; since dogs were used as their own controls, it is unlikely that this influenced the results significantly. Insulininduced rates of decline did not differ from those observed during an equimolar infusion of somatostatin under the same circumstances in the same dogs. The one clearcut difference between insulin and somatostatin infusions was in the rebound of glucagon after the termination of the latter. However, these studies provide no insights into the mechanism of suppression by either hormone and should not be construed as implying mechanistic similarity.

The foregoing results fail to demonstrate a relationship between ambient glucose concentration and the magnitude of in- sulin-mediated suppression of glucagon in dogs, and are consistent with a glucagon-lowering action of insulin that is independent of the ambient glucose concentration and that does not differ qualitatively from that of equimolar quantities of somatostatin. They further dissociate for the first time the glucagonstimulating action of hypoglycemia from the glucagon-suppressing action of insulin, which is obscured during acute insulininduced hypoglycemia.

Such independence does not necessarily exclude an insulin effect at the level of glucose transport; it is, of course, possible that insulin stimulates glucose transport into alpha cells sufficiently, even at low glucose concentrations, to suppress glucagon secretion. However, this seems unlikely, since glucose transport by purified alpha cells, which is extremely slow (18), is not believed to be enhanced by insulin (18-20). In insulin-deprived phloridzin-pretreated diabetic dogs glucose can suppress glucagon levels at a normal rate (although not to a normal level) despite the complete absence of measurable plasma insulin (12). Thus, despite their parallelism in plasma, glucose and insulin may both suppress glucagon secretion via independent mechanisms yet to be identified.

Table I. Comparison of Rates* of Insulin- and Somatostatin-induced Glucagon Decline at High and Low Plasma Glucose Concentrations

\begin{tabular}{|c|c|c|c|c|}
\hline & \multicolumn{4}{|c|}{ Rate of glucagon suppression $(\mathrm{pg} / \mathrm{ml} / \mathrm{min} ; \% / \mathrm{h})$} \\
\hline & \multirow[b]{2}{*}{$\begin{array}{l}\text { Nondiabetic dogs } \\
(n=5)\end{array}$} & \multicolumn{3}{|c|}{ Insulin-deptived diabetic dogs } \\
\hline & & $n=4$ & $n=5$ & $n=5$ \\
\hline Phloridzin pretreatment & + & - & + & + \\
\hline Fasting plasma glucose $(\mathrm{mg} / \mathrm{dl})$ & $62 \pm 3$ & $340 \pm 29$ & $77 \pm 9$ & $321 \pm 19^{\ddagger}$ \\
\hline Insulin infusion & $4.6 \pm 1.9 ; 47 \pm 8$ & $4.7 \pm 1.7 ; 48 \pm 13$ & $9.4 \pm 3.5 ; 51 \pm 8$ & $2.1 \pm 0.6^{8} ; 39 \pm 10$ \\
\hline Somatostatin infusion & $2.1 \pm 0.7 ; 35 \pm 8$ & $3.9 \pm 1.4 ; 54.6$ & $5.5 \pm 3.4 ; 31 \pm 10$ & - \\
\hline
\end{tabular}

* Rate of decline was calculated from the zero time value minus the nadir divided by the time between the zero point and the nadir. ${ }^{\ddagger} \mathrm{Hypergly-}$ cemia had been induced by glucose infusion for $120 \mathrm{~min}$ (Fig. 5). 8 In these experiments insulin was infused at a constant rate of $7.5 \mathrm{mU} / \mathrm{kg}$ per min after maximal suppression of glucagon by glucose infusion that was begun 120 min earlier (Fig. 5). 
The present studies also show that in the absence of insulin, glucose-mediated suppression of plasma glucagon is incomplete, that is, glucagon declines to a nadir that is still far above normal, and that insulin administered at this point promptly suppresses glucagon to near-normal values, but at a slower rate than when the same dogs were normoglycemic (Table I). This is consistent with but does not prove independent suppressive effects of insulin and glucose on glucagon secretion, although under physiologic circumstances their respective actions are inseparable because they normally rise in concert.

These interpretations may be relevant to the pathogenesis of diabetic hyperglucagonemia. It is possible that hyperglucagonemia observed in poorly controlled diabetes represents only the "residual" fraction of hyperglucagonemia from the insulin deficiency that hyperglycemia did not suppress. In this event, the apparent unsuppressibility of alpha cells by glucose would reflect the fact that maximum glucose-mediated suppression had already taken place, a novel interpretation. Alternatively, the hyperglycemia could have induced a refractory state or produced metabolic changes that interfere with the alpha cell response to glucose. The tissue source of the unsuppressed residual hyperglucagonemia was not determined in these studies. Earlier work in dogs (21) has demonstrated that the gastric fundus is an important source of glucagon secretion in the insulin-deprived state and that insulin is a potent suppressor. It is therefore possible that in the dog the residual glucagon levels represent gastric glucagon that is suppressed more readily by insulin than by glucose (21).

\section{Acknowledgments}

This work was supported by Veterans Administration Institutional Research Support Grant 549-8000, National Institutes of Health grant AM02700-25, and by a Diabetes Research \& Education Foundation grant. Dr. Unger is a Senior Medical Investigator, Dallas Veterans Administration.

\section{References}

1. Muller, W. A., G. R. Faloona, and R. H. Unger. 1971. The effect of experimental insulin deficiency on glucagon secretion. J. Clin. Invest. 50:1992-1999.

2. Muller, W. A., G. R. Faloona, and R. H. Unger. 1973. Hyperglucagonemia in diabetic ketoacidosis: its prevalence and significance. $\mathrm{Am}$. J. Med. 54:52-57.

3. Braaten, J. T., G. R. Faloona, and R. H. Unger. 1974. The effect of insulin on the alpha-cell response to hyperglycemia in long-standing alloxan diabetes. J. Clin. Invest. 53:1017-1021.

4. Warne, G. L., F. P. Alford, D. J. Chisholm, and J. Court. 1977. Glucagon and diabetes. II. Complete suppression of glucagon by insulin in human diabetes. Clin. Endocrinol. 6:277-284.

5. Östenson, C. G. 1979. Regulation of glucagon release: effects of insulin on the pancreatic $A_{2}$-cell of the guinea pig. Diabetologia. 17:325330 .
6. Honey, R. N., M. B. Fallon, and G. C. Weir. 1980. Effects of exogenous insulin, glucagon and somatostatin on islet hormone secretion in the perfused chicken pancreas. Metab. Clin. Exp. 29:1242-1246.

7. Mortimer, C. H., W. M. G. Turnbridge, D. Carr, L. Yeomans, T. Lind, D. H. Coy, S. R. Bloom, A. Kastin, C. N. Mallinson, G. M. Besser, A. V. Schally, and R. Hall. 1974. Effects of growth-hormone releaseinhibiting hormone on circulating glucagon, insulin, and growth hormone in normal, diabetic, acromegalic and hypopituitary patients. Lancet. i: 697-701.

8. Iversen, J. 1974. Inhibition of pancreatic glucagon release by somatostatin: in vitro. Scand. J. Clin. Lab. Invest. 33:125-129.

9. Koerker, D. J., W. Ruch, E. Chideckel, J. Palmer, C. J. Goodner, J. Ensinck, and C. C. Gale. 1974. Somatostatin: hypothalamic inhibitor of the endocrine pancreas. Science (Wash. DC). 184:482-483.

10. Samols, E., J. Tyler, and V. Marks. 1972. Glucagon-insulin interrelationships. In Glucagon. Molecular Physiology, Clinical and Therapeutic Implications. P. J. Lefebvre and R. H. Unger, editors. Pergamon Press Inc., Elmsford, NY. 151-174.

11. Buchanan, K. D., and W. A. A. Mawhinney. 1973. Insulin control of glucagon release from insulin-deficient rat islets. Diabetes. 22:801803.

12. Starke, A., S. Grundy, J. D. McGarry, and R. H. Unger. 1985. Correction of hyperglycemia with phloridzin restores the glucagon response to glucose in insulin-deficient dogs: implications for human diabetes. Proc. Natl. Acad. Sci. USA. 82:1544-1546.

13. Unger, R. H., A. M. Eisentraut, M. S. McCall, and L. L. Madison. 1962. Measurements of endogenous glucagon in plasma and the influence of blood glucose concentration upon its secretion. J. Clin. Invest. 41: 682-689.

14. Raskin, P., Y. Fujita, and R. H. Unger. 1975. Effect of insulinglucose infusions on plasma glucagon levels in fasting diabetics and nondiabetics. J. Clin. Invest. 56:1132-1138.

15. Harris, V., G. R. Faloona, and R. H. Unger. 1979. Glucagon. In Methods of Hormone Radioimmunoassay. B. M. Jaffe and H. R. Behrman, editors. Academic Press, Inc., New York. 643-656.

16. Herbert, V., K. S. Lau, C. W. Gottlieb, and S. J. Bleicher. 1965. Coated charcoal immunoassay of insulin. J. Clin. Endocrinol. Metab. 25:1375-1384.

17. Yalow, R. S., and S. A. Berson. 1960. Immunoassay of endogenous plasma insulin in man. J. Clin. Invest. 39:1157-1175.

18. Gorus, F. K., W. J. Malaisse, and D. G. Pipeleers. 1984. Differences in glucose handling by pancreatic A- and B-cells. J. Biol. Chem. 259:1196-1200.

19. Pagliara, A. S., S. N. Stillings, M. W. Haymond, B. A. Hover, and F. M. Matschinsky. 1975. Insulin and glucose as modulators of the amino acid-induced glucagon release in the isolated pancreas of alloxan and streptozotocin diabetic rats. J. Clin. Invest. 55:244-255.

20. Matschinsky, F. M., A. S. Pagliara, B. A. Hover, C. S. Pace, J. A. Ferrendelli, and A. Williams. 1976. Hormone secretion and glucose metabolism in islets of Langerhans of the isolated perfused pancreas from normal and streptozotocin diabetic rats. J. Biol. Chem. 251:60536061.

21. Blazquez, E., L. Muñoz-Barragan, G. S. Patton, L. Orci, R. E. Dobbs, and R. H. Unger. 1976. Gastric A-cell function in insulin-deprived depancreatized dogs. Endocrinology. 99:1182-1188. 